\title{
Saudi Specialist Certificate Program for Radiology Technology \& Medical Imaging: A Commentary
}

\author{
Alahmari A* \\ Department of Radiology, Al-Namas General Hospital, \\ Saudi Arabia \\ *Corresponding author: Abdulwahab Alahmari, \\ Department of Radiology, Radiology Specialist, Al-Namas \\ General Hospital, Ministry of Health, Al-Namas City, \\ Saudi Arabia
}

Received: February 22, 2021; Accepted: February 26, 2021; Published: March 05, 2021

\section{Short Commentary}

This post-bachelor program is 4 year-long program for Radiographers which is offered by the Saudi Commission for Health Specialties for Saudi Radiographers. This program has no similar programs in the UK or the US. It cost around 12,000 S.R. per year. The program's aim is to give an advanced level of training for Radiographers to become specialized in one field. The program has three tracks; ultrasound, axial imaging (CT \& MRI), and nuclear medicine.

This program is similar to the residency programs for physicians. The trainee will finish R1 to R4 like any other physician's program. The program has an admission test and the top 10 scores are selected in a matching process that includes the GPA, research, volunteering, etc. The matching system is like the matching system for physicians' programs. Every year the trainee must pass a specific test to move to the next phase of this program. After graduation, the Radiographer will be subspecialized in one field and the salary will increase.

The negative thing about this program that it can't undergo any credential evaluation process in any country globally. The program is called a fellowship program, but its design like a residency program. The scientific committee claims that there are similar programs in the US like the American Board of science in nuclear medicine and in the UK like the institute of physics and bioengineering in medicine. A bachelor's degree, master's degree, or Ph.D. can be processed, but a fellowship program that is 4 years for radiologic technologists is very confusing.

The program accepts 12 yearly which is a low number in different centers in the kingdom. The program's supervisors in some centers do follow the educational formatting and some of the mentors do not follow the requirements since the Saudi Commission for Health Specialties does not pay the supervisors and mentors nothing which makes the Saudi Commission for Health Specialties have no way in control them. In some cases, it can result in the trainee not passing the annual exam or shut down the training center. The training centers are not given support from the Saudi Commission for Health Specialties to help them to improve their teaching methods and practice.

This program does not focus on research and publishing papers, but in the program, there are some modules about research. furthermore, after finishing the program the radiologic specialist will become a radiologic subspecialist, not a consultant. No Dr. title is added before the graduate name and no degree title is added behind the name for example (B.Sc., M.Sc., P.hD., RRA, FRCR, etc). even though it's a clinical doctorate degree but no doctor title is given. Many information is missing and many questions about this program need to be addressed.

The program did not have specialties like angiography and interventional radiology. The name of this program is a very long name which should be shorter. The good thing about this program is allowing an equal number of male and female radiographers (top 6 males and top 6 females scores).

This program required a clinical experience from 2 to 3 years before the candidate can be accepted which illogical because the trainee will have training for 4 years in this program which will teach the trainee all what they need to know in selected specialty.

This program need to be revaluated and redesigned to be more inclusive to different fields and to give a new rule for radiographers. Any organization want to propose a new program must study the credential evaluation point very carefully. The future of the graduates from similar programs can be wasted.

\section{Reference}

1. Saudi Commission for Health Specialties. Saudi Specialist Certificate Program For Radiology Technology \&amp; Medical Imaging. SCFHS. 2011.
Austin J Radiol - Volume 8 Issue 2 - 2021

ISSN : 2473-0637 | www.austinpublishinggroup.com

Alahmari. (C) All rights are reserved 